\title{
«Descendientes de los primeros». Las probanzas de méritos y servicios y la genealogía cacical. Audiencia de Charcas, 1574-1719
}

por

M. Carolina Jurado ${ }^{1}$

Universidad de Buenos Aires/CONICET

El presente artículo propone abordar las probanzas de méritos y servicios de renombrados linajes cacicales de Charcas colonial, a partir de una imagen problematizadora que dé cuenta del modo en que se desarrollaba la escritura del documento legal, dirigiendo la mirada al actuar de los notarios, procuradores y asesores legales, como piezas clave en la adecuación y transmisión de su contenido. La lectura comparativa de distintas probanzas de méritos revela la emulación de un modelo arquetípico de liderazgo, en los intersticios del formulismo hispano. Se aspira asi a proporcionar reflexiones sobre el uso de las probanzas de méritos para el conocimiento del pasado prehispánico y colonial.

Palabras Clave: probanzas de méritos y servicios; notarios; genealogía; líderes indígenas; Charcas colonial.

\section{INTRODUCCIÓN}

Sin lugar a dudas, las Relaciones o Probanzas de Méritos y Servicios constituyen una de las principales fuentes documentales para el estudio de la historia social colonial. Documentación persuasiva, escrita según estrictos

${ }^{1}$ Doctora en Historia (Universidad de Buenos Aires). Investigadora Asistente del Consejo de Investigaciones Científicas y Técnicas (CONICET). Programa de Historia de América Latina (PROHAL), Instituto de Historia Argentina y Americana «Dr. E. Ravignani», Facultad de Filosofía y Letras, Universidad de Buenos Aires, 25 de Mayo, 217, Ciudad Autónoma de Buenos Aires, República Argentina. Correo electrónico: jurado_carolina@yahoo.com.ar Agradezco los comentarios realizados por la Dra. Ana M. Presta a versiones previas del presente trabajo y las sugerencias de los evaluadores de Revista de Indias. 
modelos legales, las probanzas de méritos narran hazañas y méritos del peticionario y de sus antepasados en vistas a solicitar a la Corona recompensas materiales y simbólicas por sus honras y servicios. Numerosos conquistadores españoles, imbuidos de una mentalidad jerárquica y señorial, y animados por el éxito de las armas, lograron que sus actos en el Nuevo Mundo les proporcionaran honor, fama gloria y bienestar material. Las probanzas de méritos permitieron a muchos de ellos reconstruir su pasado y hasta reinventar $\mathrm{u}$ ocultar su propia historia familiar a fin de convencer al rey del otorgamiento de la ansiada gracia o merced $^{2}$.

Emulando a los españoles, líderes indígenas e indios principales de Charcas colonial ${ }^{3}$ inundaron los ámbitos judiciales, informando sobre sus méritos, servicios, antepasados y glorias al rey de España a fin de obtener honores y exenciones. Sus probanzas de méritos y servicios recibieron la atención de la historiografía andina en los últimos cuarenta años, dentro de una mirada interpretativa que pretendía «traspasar» el documento a fin de rescatar la oralidad perdida ${ }^{4}$; un acercamiento que, en líneas generales, resultó más extractivo que crítico y contextual. Así, las probanzas de méritos de renombrados linajes kurakales -entendidas como «más indígenas» que otra documentación colonial- se analizaron por el contenido que revelaban del pasado prehispánico de las amplias parcialidades que los líderes andino coloniales sostenían haber gobernado $^{5}$, como enunciación de un nuevo discurso colonial ${ }^{6}$, a partir de la teoría del discurso ${ }^{7}$ y por sus aspectos simbólicos y legitimantes ${ }^{8}$. Sin embargo, ninguna de ellas se interrogó aún por el contexto histórico de producción del documento legal que, en sí mismas, constituyen. ¿Es posible interpretar los relatos genealógicos incluidos en las probanzas de méritos indígenas sin reflexionar acerca del contexto de emergencia del documento, tanto en torno a la trama legal y social en la que se dirimía su redacción, como en relación

\footnotetext{
2 Lockhart, 1982. Macleod, 1998. Presta, 2000.

3 Se utiliza la expresión Charcas colonial o jurisdicción de la Audiencia de Charcas -esto es, desde Ayaviri, al sur del Cusco, hacia el sur- para dar cuenta del espacio geo-político del que provienen los líderes indígenas cuyas probanzas de méritos y servicios se consideran en el presente artículo. Sin embargo, es importante tener en cuenta que en tiempos prehispánicos y temprano coloniales se reconocía una diferencia entre la región del Collao, en el área del Lago Titicaca, y la región de Charcas, diferenciación que, con seguridad, estuvo presente en la memoria de los testigos y peticionarios indígenas analizados. Pärssinen, 2003: 232-238.

4 Martínez, 1995: 254.

5 Espinoza Soriano, 1969; 1981. Medinacelli y Arze, 1996; 1998. Choque Canqui, 1997; 2003. Abercrombie, 2006. Platt, Bouysse-Cassagne y Harris, 2006.

6 Graña, 2000; 2001.

7 Medinacelli, 2004.

8 Morrone, 2010.
} 
a su funcionalidad y a los usos del modelo genealógico en el contexto político de los Andes coloniales postoledanos e, incluso, del mundo hispánico más amplio?

En ese marco, el presente trabajo propone una aproximación a las probanzas de méritos y servicios de un sector específico del mundo indígena, esto es, de aquellos que ocuparon roles de liderazgo, que trascienda la dicotomía verdad-mentira para reflexionar sobre las formas de percibir, recordar, adecuar, transmitir y registrar por escrito el pasado andino en contextos legales y socio-políticos específicos. Desde esta perspectiva, las probanzas de méritos y servicios kurakales se presentan al investigador como un complejo desafío metodológico y hermenéutico. Con este propósito, se recurre en primer lugar al análisis de la estructura formal y del modo en que se desarrolló la escritura del documento, dirigiendo la mirada al accionar de los notarios, procuradores y asesores legales como piezas claves en la adecuación y transmisión de su contenido. A partir de allí, la lectura comparativa de las probanzas de méritos y servicios de algunos de los linajes cacicales más renombrados de la jurisdicción de la Real Audiencia de Charcas, en un marco temporal amplio (1574-1719), permite trascender las especificidades de casos empíricos concretos y revela la emulación de un modelo arquetípico de buen kuraka en los intersticios del formulismo hispano. Se aspira así a brindar una mirada crítica del discurso genealógico kurakal, proporcionando reflexiones sobre el uso de las probanzas de méritos para el conocimiento del pasado prehispánico y colonial.

\section{La Probanza de Méritos y Servicios como escritura legal: EL ROL DE NOTARIOS, PROCURADORES Y OTROS ASESORES LEGALES}

Surgidas de la idea peninsular medieval de obligaciones mutuas, las probanzas de méritos y servicios constituían un género de escritura legal que se estructuraba en torno al recuento de los logros y actos del peticionario, y los méritos adquiridos por las virtudes de sus antepasados, a fin de solicitar a la Corona mercedes y recompensas por los servicios prestados ${ }^{9}$. Las probanzas de méritos y servicios contenían un extenso y detallado interrogatorio $\mathrm{y}$, a continuación, los testimonios de un número importante de testigos; asimismo el traslado o copia de otro tipo de documentación legal que respaldaba lo afirmado. Con el mismo espíritu probatorio, los documentos conocidos como Informaciones de Filiación presentaban interrogatorios y testimonios más aco-

9 Macleod, 1998: 25. 
tados en extensión y, sobre todo, tendientes a demostrar genealogías y parentescos convenientes en virtud de lo solicitado, por lo cual también son considerados en este análisis.

Los referentes inmediatos de las probanzas de méritos y servicios son las Cartas Ejecutorias de hidalguía, cuya producción se extiende en la Península desde fines del siglo XV hasta comienzos del siglo XVIII. Justificación ideológica de la sociedad estamental, las cartas ejecutorias se originaron en el avance de los concejos municipales sobre la definición jurídica de las personas por razones fiscales, judiciales y sociales. Este proceso generaba una tensión latente entre las autoridades y aquellas personas que se consideraban a sí mismas merecedoras del estatus de hidalguía, cuyas demandas fueron en aumento. La profunda división de la sociedad peninsular por la jerarquía del rango se sustentaba en el mérito, la virtud y, sobre todo, en una «cultura genealógica» o «del linaje» que contaba con la memoria histórica como garantía de prestigio, honorabilidad y respeto. En este contexto, las cartas ejecutorias se convirtieron en instrumentos generadores $\mathrm{y} / \mathrm{o}$ protectores de privilegios, títulos y derechos, al incluir testimonios que dieran cuenta de la adscripción -real o posible- de los interesados a un linaje de hidalgos, su genealogía, solar y cargos de los litigantes y de sus antepasados ${ }^{10}$. La formulación de un pasado glorioso, que incluyera los orígenes del linaje en torno a un padre fundador virtuoso, un tronco común, hazañas sublimes y fuerte herencia simbólica -como un apellido, blasones y escudos de armas- tenía mucho de creación y de realidad representada. La remota antigüedad de numerosas genealogías nobiliarias castellanas, con ancestros vinculados a la nobleza troyana, patricios romanos y/o parentescos con la Virgen María, era una formulación ideal y ficticia, una invención del pasado y un reacomodamiento de la memoria familiar a fin de dar duración, prestancia y nobleza al linaje ${ }^{11}$. Es el caso, por ejemplo, de los Girón, cuyo ancestro fundador, don Pelayo Peláez, había salvado en el siglo XII al rey Alfonso VII en batalla; o bien, el más cuestionado de Mateo Vázquez de Leca, secretario personal del rey Felipe II, sospechado por sus pares de comprar la testificación de aristócratas italianos para tejer una complicada genealogía que lo vinculaba con la República romana y los emperadores de Oriente ${ }^{12}$.

En el Nuevo Mundo, la conquista y colonización proporcionó a numerosos españoles y a sus descendientes la oportunidad para informar sus supuestas

\footnotetext{
10 Ruiz García, 2006. Atienza Hernández, 1998. Álvarez-Ossorio Alvariño, 2006.

11 Atienza Hernández, 1998: 10-11. Para Florencia en los siglos XIV y XV, ver Klapisch-Zuber, 1982.

12 Atienza Hernández, 1998: 19. Álvarez-Ossorio Alvariño, 2006: 146. Lovett, 1977: 3-10.
} 
hazañas al rey mediante probanzas de méritos y servicios e informaciones de filiación que les permitieran el ascenso y/o reconfirmación de su estatus social, tanto como la legitimación de una situación privilegiada de hecho. A los conquistadores se sumaron con rapidez miembros de las élites indígenas, convirtiendo las probanzas de méritos y servicios e informaciones de filiación en unas de las principales escrituras legales presentadas en los ámbitos judiciales coloniales y peninsulares. Las probanzas de méritos y servicios indígenas, elaboradas con el objeto de posicionar al interesado en el sector beneficiado de la sociedad colonial, constituyen una respuesta indígena al imperativo de la conquista. Son, en sí mismas, el producto de una «semiosis colonial», de un complejo sistema de interacciones discursivas en un contexto que refiere a la relación entre discurso y dominación, apropiación y resistencia, en el marco de la difusión de la literalidad occidental ${ }^{13}$. Esta perspectiva nos lleva a focalizar en el lugar enunciativo del discurso colonial analizado, cuya configuración depende tanto de lo que se quiere demostrar como de la coexistencia de previos lugares de enunciación desde los que se construyeron tales imágenes de la realidad.

Para el líder indígena, o aquel que aspirara a serlo, las probanzas de méritos y servicios adquirían un valor adicional pues ellas se tornaron necesarias para obtener sustento judicial en el acceso y sucesión en el cacicazgo, al reconocer los lazos genealógicos con antiguos gobernantes locales. Si bien importantes funcionarios y cronistas negaron en los Andes el derecho hereditario en la sucesión al cacicazgo ${ }^{14}$, la Corona no aceptó sus puntos de vista. La Real Cédula del 2 de febrero de 1603 sostenía la obligación de respetar la costumbre de sucesión hereditaria en los cacicazgos andinos; decisión confir-

13 La expresión «semiosis colonial» refiere una red de prácticas semióticas coloniales resultantes del encuentro entre normas hegemónicas y valores que guían las prácticas semióticas en los centros metropolitanos, su extensión a las regiones coloniales y la resistencia y adaptación que ellas generan desde la perspectiva de la población dominada. Mignolo, 1992a: 43; 1992b: 808 .

14 Entre aquellos que sostuvieron que los kuracazgos y sus autoridades habían sido creados por Topa Inca, negando derechos hereditarios de gobierno a los líderes indígenas, se encontraban Hernando de Santillán, Polo Ondegardo, Juan de Matienzo, el Virrey don Francisco de Toledo, Pedro Sarmiento de Gamboa y el Virrey don Martín Enríquez. Claramente, la afirmación de la intervención del Inca en el gobierno de los grupos étnicos anunciaba el control de la administración colonial sobre el sistema de autoridades de las poblaciones conquistadas. Ondegardo, 1917. Santillán, 1968 [1563]. Matienzo, 1967 [1567]. Sarmiento de Gamboa, 1942 [1572]. Para una visión sintética de las ideas del Virrey Toledo y del Virrey Enríquez, véase la Carta del Virrey Toledo a S.M., Cuzco, 25 Marzo 1571 (Levillier, 1924, vol. III: 443) y Probanza del gobierno y costumbres de los ingas por orden del Virrey Enríquez, Archivo General de Indias, Sevilla (AGI), Lima, leg. 30. 
mada por la Real Cédula de 19 de julio de $1614^{15}$. Se ordenaba a las Audiencias que entendieran en los pleitos sucesorios, conservando los derechos de los «caciques o principales descendientes de los primeros». ${ }^{16}$ De este modo, la dignidad cacical debía recaer en un individuo en virtud del derecho de sangre, estatus que ante la legislación colonial concedía una situación de privilegio merced a lo ancestral de su origen.

La necesidad de los líderes indígenas de demostrar su pertenencia a un linaje que, generación tras generación, hubiera ejercido el rol de liderazgo en la «república de indios» a fin de obtener confirmación o acceso al cargo al que aspiraban, daba a sus probanzas de méritos e informaciones de filiación un complejo y peculiar contenido. Ambos documentos fueron sintomáticos de la capacidad de los líderes andinos $-\mathrm{y}$ de los indígenas en un sentido más amplio- de adaptarse al sistema jurídico colonial y de utilizarlo a su favor al tiempo que revelaron los posibles límites a esa integración ${ }^{17}$.

En su argumentación legal, los líderes indígenas debieron buscar la ayuda de notarios, procuradores ${ }^{18}$, escribientes ${ }^{19}$, abogados ${ }^{20}$, oficiales menores del sistema judicial y otros asesores legales. Ellos eran quienes en distintas etapas aconsejaban, registraban -por escrito, en castellano y con el formato y formulismo legal requerido-y, por último, certificaban sus relatos genealógicos, hazañas y méritos que, cumpliendo las etapas de presentación, podrían convencer al juez de premiar al litigante. La élite indígena andina destinó importantes recursos monetarios y materiales para remunerar el asesoramiento y los servicios legales de letrados, procuradores, escribanos y solicitadores que supieran iniciar una causa judicial21. Inclusive, varios ejemplos permiten sugerir la existencia de connivencias, vínculos estrechos y alianzas de ciertos

15 Díaz Rementería, 1977: 49.

16 Recopilación de Leyes de Indias, Libro VI, Título VII, Ley Primera: Que las Audiencias oigan en justicia a los indios sobre los cacicazgos.

17 Stern, 1982: 216-218.

18 Según el vocabulario del siglo XVII, existen varios tipos de procuradores (de cortes, de causas, de la villa), haciendo referencia al verbo «procurar» o solicitar alguna cosa. Covarrubias, 1943 [1611]: f. 595r.

19 El término se refiere al «que escribe dictandole otro, o el que está en el escritorio de algun escrivano, o secretario que escrive y copia lo que se le ordena». Covarrubias, 1943 [1611]: f. 368r.

20 En su diccionario, Covarrubias glosa el término como «el letrado que defiende, o acusa a alguno en juyzio, del verbo abogar». Covarrubias, 1943 [1611]: f. 5v.

21 Así lo explicitan, por ejemplo, diversos indígenas de los repartimientos de Luringuanca y Ananguanca, Jauja, a fines del siglo XVI. Según el testigo don Carlos Apoalaya, «(...) el dicho su padre gastó en el dicho pleito hasta que murió siete mil pesos en plata en letrados, procuradores e lenguas y otras cosas y escrivanos». Medelius y de la Puente Luna, 2004: 68. 
indígenas con determinados letrados, notarios y funcionarios judiciales, cuya confianza mereció la recurrencia a sus servicios en distintas ocasiones ${ }^{22}$. Notarios, procuradores, abogados y asesores legales son piezas claves al tratar de aproximarnos al estudio de las múltiples aristas de una probanza de méritos indígena pues ellos aconsejaban a los kurakas y redactaban un documento legalmente válido para la consideración del juez.

Los notarios eran principalmente funcionarios autorizados para dar fe en tanto presunción legal de veracidad en los documentos públicos ${ }^{23}$. A lo largo de los siglos XV y XVI, la Corona aumentó el control sobre los exámenes y sobre las reglas que regían el uso del oficio notarial. Todo escribano debía respetar una serie de condiciones generales según la legislación para la correcta redacción del documento público, en relación al tipo de letra, cantidad de renglones y folios, $\mathrm{u}$ ordenamiento de las partes ${ }^{24}$. Los escribanos recurrían a los formularios notariales - colecciones de fórmulas que servían como ar-

22 Así, por ejemplo, existía un estrecho vínculo comercial entre el capitán de mita de los lupaqa, don Diego Chambilla, y el escribano de Su Majestad, Pedro Mateos, vecino de la Villa de Potosí, quien no sólo era su apoderado en asuntos económicos sino quien cuidaba y criaba a su hijo en Potosí (Murra, 1978). Asimismo, el doctor Barros de San Millán, educado en Salamanca y oidor de la Audiencia de Charcas, se erige como el caso ejemplar de confianza y alianza entre el escribano y su cliente. Acusado en su época de relaciones informales con líderes indígenas y negros libertos, Barros se propone como posible autor del Memorial dirigido al Rey por los líderes indígenas de Charcas, en el cual los mallku de importantes grupos del Surandino trazaron sus linajes cuatro o cinco generaciones atrás, reclamando recompensas y beneficios mediante la pluma de un jurista familiarizado con los procedimientos administrativos y con el mapa étnico de Charcas (Murra, 1998). Asimismo, Ana María Presta llamó la atención sobre el accionar de los hermanos Juan y Agustín de Herrera, escribanos bilingües de La Plata, quienes oficiaron de consejeros y funcionarios predilectos de la élite indígena de la ciudad (Presta, Ana M., "Redes de tinta y poder. Escribanos, clero e indígenas en la ciudad de La Plata, siglo XVI". Ponencia presentada en VIII Congreso de Etnohistoria, Sucre, Bolivia, 2011).

23 Álvarez-Coca González, 1987.

24 Si bien las Partidas de Alfonso X contenían una ordenación general de la institución notarial, ocupó máximo protagonismo la Pragmática de Alcalá de Henares de 1503, con la cual los Reyes Católicos aspiraron a regular la forma en la que debían redactarse los distintos negocios jurídicos, incluso la letra, los renglones y las palabras que compondrían las diferentes escrituras en los Libros de Protocolos. Según su Capítulo VII, las notas debían tomarse en letra cortesana y los folios debían contener al menos 35 renglones, sin dejar grandes márgenes. En cuanto al texto propiamente dicho, la Pragmática indicaba una serie de cláusulas obligatorias: en primer lugar, la indicación de las personas que otorgaban la escritura, con «fe de conocimiento» del escribano; luego la fecha completa - día, mes y año- y el lugar, haciendo constar todos los datos sin abreviaturas. Las firmas de los presentes y del escribano cerrarían el documento, luego del salvado de las enmiendas, ya fueran errores de redacción, tachaduras o últimas correcciones. Guajardo-Fajardo Carmona, vol. I, 1995: 142-144. 
quetipos o modelos para redactar escrituras-y, desde mediados del siglo XVI, a la literatura notarial especializada que comenzó a circular en España y en América para guiar la práctica legal. Se han registrado más de cuarenta obras dedicadas exclusivamente al ejercicio notarial, especialmente a la redacción de escrituras ${ }^{25}$, con recomendaciones específicas sobre la forma de ejercer el oficio y de enmarcar el vocabulario y los actos de las personas dentro de las fórmulas legales correctas.

Entre los manuales destinados a orientar a los notarios, el de Gabriel de Monterroso y Alvarado tuvo amplia circulación en los Andes. Su Practica civil y criminal \& instrucción de escrivanos [1563] gozó por Real Cédula del 5 de febrero de 1569 del monopolio exclusivo para su venta en Indias durante 20 años y aparecía en casi todas las listas de libros en Lima en la década de $1580^{26}$; incluso, años más tarde, el conocido cronista indígena Guamán Poma de Ayala fomentaba su lectura ${ }^{27}$. Como tantos otros, Monterroso brindaba un modelo de interrogatorio para examinar testigos en probanzas de hidalguía, centrado en torno a la averiguación de la antigüedad del linaje y descendencia por línea directa de varón y la legitimidad de los nacimientos. Cuestiones como la calidad y reputación de hidalgo del interesado y de sus antepasados, la existencia de un solar conocido, la exención de pechos y tributos, el uso de símbolos, preeminencias y distinciones de nobleza, su fama entre los ancianos y el carácter «público y notorio» de toda esta información constituían referencias obligadas, según recomendaciones del notario ${ }^{28}$.

Junto a ello, escribanos y asesores legales se nutrían de un discurso nobiliario, centrado en valores y nociones de sangre, linaje, honor, legitimidad, varonía, fama y reconocimiento público como pilares de la nobleza ${ }^{29}$, difundido por conocidos tratadistas de hidalguía peninsulares, como Fernando Mejía, Juan de Otalora y Bernabé Moreno de Vargas, que advertían sobre el origen, características, estatus y modos de distinción del estamento nobilia-

25 Luján Muñoz, 1981. Burns, 2005.

26 Leonard, 1996: 187.

27 Guamán Poma de Ayala, 1987 [1615]: 359.

28 Monterroso, 1563: 121-125.

29 A esto remite cierto formulismo reiterado en las probanzas de méritos y servicios, españolas e indígenas por igual, tales como: «... hijo legitimo de padres conocidos [...] por linea reta de baron sin bastardía [...] nieto legitimo de ... y visnieto de [...] fue casado e belado según horden de la santa madre yglesia con ... y deste matrimonio hubieron y procrearon por su hijo mayor legitimo a [...] por tal se lo vio criar este testigo» y «... ser publico y notorio y tradición», entre otras. 
rio $^{30}$. Sus obras dan cuenta del debate suscitado en torno al concepto mismo de nobleza durante los reinados de Carlos I y Felipe II, al verse influenciados los valores nobiliarios castellanos - centrados en la reconquista y la guerrapor los nuevos modos de comportamiento de las cortes flamenca e italiana, ligados a las tareas gubernativas y a la vinculación con el rey. La sangre, transmisora durante generaciones de la virtud y el mérito de los ascendientes del linaje y capaz de brindar derecho a exigir dignidades, privilegios y mercedes, pierde terreno en tratadistas como Moreno de Vargas frente al poder del príncipe para sancionar el ascenso social según los servicios gubernamentales y pecuniarios prestados para las necesidades del reino ${ }^{31}$. Ambos criterios difieren o se entrelazan en distintas probanzas de méritos indígenas y españolas del mundo andino colonial según su época, como si su discurso siguiese cuidadosamente los vaivenes de la discusión contenida en los tratadistas nobiliarios peninsulares. Ya advertía Murdo Macleod que los documentos probatorios conocidos como probanzas de méritos y servicios constituyen documentos falaces y exagerados, útiles para la autopromoción más que al quehacer histórico ${ }^{32}$.

Procuradores, asesores con entrenamiento legal formal y escribientes también solían redactar peticiones, a menor costo que los notarios. Muchos clientes acudían a las notarias con un asesoramiento legal previo, con instrucciones precisas y escritas a mano ${ }^{33}$; en sintonía, diversos kurakas de la Audiencia de Charcas solicitaron a la justicia el inicio de probanzas de méritos y servicios, provistos de interrogatorios redactados previamente y firmados por el peticionario y un licenciado que luego no formaría parte del proceso. Así, en 1575 don Juan Colque Guarache, capitán de mita de los quillacas y asanaques, firmaba al pie de un interrogatorio de veintidós preguntas acerca de su ascendencia y servicios realizados a Su Majestad, junto al licenciado Campuzano,

30 Desde fines del siglo XV y durante los siglos XVI-XVII se distinguieron Fernando Mexía, Libro intitulado nobiliario perfetamente copylado y ordenado por el onrado cavallero Fernando Mexia, vente y quatro de Jaen, Sevilla, 1492; Juan Arce de Otalora, De nobilitate et immunitatis hispaniae causis, quas hidalguia apellant, Granada, 1553; Juan Arce de Otalora, Summa nobilitatis hispanicae et inmunitatis regiorum tributorum causas, Salamanca, 1559; Juan García de Saavedra, Tratactus de hispanorum nobilitate, Alcalá de Henares, 1557; Bernabé Moreno de Vargas, Discursos de la nobleza de España, Madrid, 1622. Para un análisis de su contenido, véase Álvarez-Ossorio Alvariño, 2001: 42-43.

31 Álvarez-Ossorio Alvariño, 2001.

32 Macleod, 1998: 28.

33 Burns, 2010: 80. 
quien se desempeñó como fiscal de la Audiencia de La Plata ${ }^{34}$, aunque en dicha ciudad el proceso lo llevaría adelante el escribano Pedro Juárez de Va$\operatorname{ler}^{35}$. Similar situación encontramos en otras oportunidades ${ }^{36}$; podemos imaginar entonces que distintos lazos materiales y simbólicos unían a líderes indígenas con una red de funcionarios, abogados, procuradores, escribientes y/o consejeros de confianza quienes asesoraban sus presentaciones legales, encuadrando el relato indígena en el formulismo legal y los conceptos peninsulares de linaje, fama y honor, a fin de lograr los resultados efectistas esperados por los litigantes. Así lo sugiere el testamento de un reconocido líder indígena charqueño, don Juan Aymoro, cacique gobernador del repartimiento de Yamparaes, quien reconocía a su amigo Ramiro de Zúñiga por la ayuda prestada en todos sus pleitos y negocios por más de once años, tanto a él como a don Francisco Aymoro, su padre ${ }^{37}$.

En la notaría, una multiplicidad de actores sociales -oficial mayor, oficiales plumeros, oficiales menores o escribientes-acompañaba la redacción del documento ${ }^{38}$. Los errores y las tensiones producidas pueden haber sido múltiples si incorporamos su presencia y deben considerarse como parte de toda escritura pública. Muchos notarios sólo tomaban la nómina de testigos y luego hacían redactar las respuestas a sus ayudantes sin estar el testigo presente $^{39}$. En algunos casos la información era tan genérica que obligaba al

34 Del licenciado Ruy Vázquez Campuzano, fiscal de la Audiencia que residía en La Plata, donde falleció (1580-1584), AGI, Contratación, leg. 217 A, Ramo1.

35 El 14 de marzo de 1575, Pedro Juárez Valer recibió por Real Cédula la provisión del título de escribano de cámara, AGI, Charcas, leg. 418, 1. 1, f. 273v-274r.

36 Es el caso del Interrogatorio contenido en la probanza de méritos y servicios [1583] de don Fernando Ayavire y Velasco, cacique gobernador del repartimiento de Sacaca, firmado por el licenciado Melchor de Ayala, aunque el proceso se llevó delante del escribano Francisco López de Rivera. La misma situación evidencia su hijo, don Juan Ayavire Coysara, cuyo Interrogatorio [1598] fue firmado por el licenciado Joan de Espinosa mientras que el resto del proceso se llevó delante del escribano de cámara Joan Francisco Rocaforte. Por último, el Interrogatorio de la probanza de méritos y servicios [1638] de don Fernando Ayra de Arriuto, cacique gobernador del repartimiento de Pocoata, llevaba la firma del licenciado Calderón y Contreras, mientras que el proceso fue llevado adelante por el escribano Pedro Osorio.

37 Presta, Ana M., "Los Aymoro, caciques de los yamparas. ¿Un linaje ancestral o una construcción colonial toledana?", Conferencia pronunciada en La Paz, el 16 de noviembre, con motivo de su ingreso a la Academia Boliviana de Historia, 2011.

38 Muchos de estos copistas deben haber sido ayudantes aprendices, pues la práctica peninsular continuó en el Virreinato del Perú: el ayudante realizaba distintas tareas, entre ellas, copiar las fórmulas de los documentos. Sólo después de unos años y varios maestros, el aprendiz enviaba un memorial a la corte solicitando el título de escribano en las Indias. Lockhart, 1982: 93.

39 Monterroso, 1563: 7. 
oficial a emplear sus conocimientos y discreción. Francisco González de Torneo, autor del libro Práctica de escrivanos [1587], advertía a los notarios que no quitaran partes cruciales de los testimonios del testigo ${ }^{40}$. Esta denuncia de lo que era una práctica usual entre los notarios advierte sobre el contenido de nuestros documentos: ¿cuántos testimonios fueron dirigidos, abreviados o acaso reinventados por el notario o por sus ayudantes lejos de la mirada del testigo? Esto parecería sugerir respuestas como «A las diez y seis preguntas dixo que fue publico lo que la pregunta dize aver pasado assi como en ella se contiene» ${ }^{41}$, e incluso, "A las once preguntas dijo que lo contenido en la pregunta lo ha oido decir por publico e notorio» ${ }^{42}$. Si a ello sumamos, en los casos de testigos indígenas, ladinos o no, el rol del intérprete y su capacidad para transmitir y reinterpretar la respuesta, podemos adicionar a nuestra lista dudas acerca de testimonios como: "A la quinta pregunta dixo que es ansi como la pregunta lo dize»; "A la ocho dice que si», entre otras ${ }^{43}$. En síntesis, ¿qué testimonios, qué voces están registradas bajo la respuesta juramentada del testigo? ¿Cuántos testimonios se obtuvieron a cambio de arreglos informales? Ya advertía Monterroso la responsabilidad del notario de descubrir testigos sobornados que repetían sin cambios el contenido de las preguntas; práctica denunciada también por el Virrey don Francisco de Toledo ${ }^{44}$. ¿Acaso la presencia de los testigos españoles Toribio de Alcaraz y Juan de Espinosa, afirmando la legitimidad del líder indígena don Juan Colque Guarache en su probanza de méritos y servicios, pero negándola años más tarde en la probanza de méritos de su enemigo, el cacique gobernador don Fernando Ayavire y Velasco, no sugiere esta práctica ${ }^{45}$ ?

Interrogatorios cuidadosamente elaborados a la luz de las recomendaciones de tratados notariales y nobiliarios, preguntas que inducen las respuestas en

40 En su Libro Sexto: "En lo que toca a examinar los testigos della, se ha de advertir que se ha de escribir por la orden que el testigo lo dixere sin dexar de poner, ni mudar cosa ninguna en sustancia”. González de Torneo, 1587: 145.

41 Testigo Antonio Quijada, vecino de la ciudad de La Plata, 7 de diciembre de 1583. "Probanza de méritos y servicios de don Fernando Ayavire y Velasco, cacique gobernador del repartimiento de Sacaca", Memorial de Charcas, 1986: 83.

42 Testigo don Pablo Humiro, cacique de Moromoro. "Probanza de méritos y servicios de don Juan Colque Guarache, capitán de mita de los quillacas y asanaques [1575]”, Espinoza Soriano, 1981: 242.

43 Jurado, 2010: 297.

44 En relación a los pleitos desarrollados entre los indígenas de los repartimientos de Ananguanca y Luringuanca, el Virrey don Francisco de Toledo sostenía que « (...) lo peor es en mucha corruction de sus costumbres porque de tratar los dichos pleytos se ha mostrado abuso por testigos falsos», Medelius y de la Puente Luna, 2004: 77.

45 Graña, 2000: 550. 
función de lo que se quiere resaltar, testimonios redactados sin la presencia del testigo, intermediaciones lingüísticas, testigos sobornados y aleccionados en sus respuestas, testimonios indígenas que replican el pasado prehispánico mediante conceptos peninsulares como hidalguía, primogenitura y varonía: todos estos aspectos deben estar presentes en la mirada del investigador a la hora de abordar una probanza de méritos y servicios indígena. Ya advertía Juan de Solórzano y Pereyra [1648] que en los casos de pleitos por cacicazgos «...cada pretensor prueba siempre lo que articula y vienen los jueces a hallarse confusos en esta igualdad de probanzas que de ordinario son de fama y de oidas $\rangle^{46}$.

Por ello, el jurista recomendaba a sus colegas que, para resolver los juicios de liderazgo indígena que pasaban por sus manos, prefirieran antes que las probanzas con testigos, los testimonios de padrones y listas que recuperaban parentescos y nombres de descendientes para otros fines. Las probanzas de méritos y servicios indígenas no son directas ventanas al pasado sino que ellas mismas implican una complejidad que reside en el documento mismo, como portador de múltiples mensajes.

\section{PRoBANZAS DE MÉRITOS Y SERVICIOS INDÍGENAS: GENEALOGÍAS Y LINAJES CACICALES EN CHARCAS COLONIAL}

Entre 1574 y 1598 cinco importantes líderes indígenas de la jurisdicción de la Audiencia de Charcas presentaron sus probanzas de méritos y servicios solicitando mercedes al rey de España. Don Juan Colque Guarache, capitán de mita de los quillacas y asanaques (Urcosuyo) (en tres oportunidades: 157475, 1576-7 y 1580), don Fernando Ayavire y Velasco, cacique gobernador del repartimiento de Sacaca (en 1583-84), don Francisco Aymoro, cacique gobernador del repartimiento de Yamparaes (en 1586), su hijo don Juan Aymoro, cacique gobernador del mismo repartimiento (en 1592-97) y don Juan Ayavire Coysara, cacique gobernador del repartimiento de Sacaca (en 1598-99) elaboraron junto a sus notarios y asesores legales largos recuentos que ordenaron a sus antepasados en torno al concepto castellano de linaje. Otros líderes emularon esta práctica en los siglos posteriores, como don Fernando Ayra de Arriutu, cacique gobernador del repartimiento de Pocoata (1638) y don José Fernández Guarache, cacique gobernador del repartimiento de Jesús de Machaca, en 1719.

Estos litigantes ocupaban cargos importantes en la «republica de indios», como el de cacique gobernador de repartimiento, alcalde de naturales, capi-

46 Solórzano y Pereyra, 1972 [1648], vol. I: 410. 
tanes de mita o maestre de campo ${ }^{47}$. Todos ellos eran indios ladinos, hablaban y/o escribían el castellano y habían adoptado las costumbres de los españoles; de hecho, la ladinidad de don Francisco Aymoro, más que su supuesta herencia genealógica, aparece como una de las claves interpretativas centrales de su acceso al poder ${ }^{48}$. Asimismo, los litigantes se desempeñaban como hábiles participantes de los mercados y de la justicia colonial, rigiendo su patrimonio, herencia y última voluntad de acuerdo a la normativa hispana ${ }^{49}$. Todos ellos se presentaron en sus probanzas de méritos y servicios como indios hábiles y de buen entendimiento, acompañados ordinariamente por españoles y vestidos a su usanza:

...hombre de mucha razón. Don Juan Colque Guarache [1576-77] ${ }^{50}$. ... avil y suficiente. Don Fernando Ayavire y Velasco [1583 ${ }^{51}$.

...hombre de bien i de tan buen entendimiento y persona de mucha razón i todo buen termino [...] que habla la lengua española i bestido en abito de español. Don Francisco Aymoro [1586 ${ }^{52}$.

...de tan buen entendimiento y capacidad, puntualidad, verdad y buen trato $[\ldots]$ con mucho lustre y adorno en hábito de español [...] comunicando y acompañándose siempre con hombres principales españoles. Don Fernando Ayra de Arriutu $[1638]^{53}$.

47 El capitán de mita era un líder indígena al mando y responsable de la entrega de cada contingente mitayo. Por su parte, el alcalde de naturales era la autoridad indígena que se vinculaba al cabildo indígena como alcalde ordinario, o bien, como alcalde mayor presidía el municipio con jurisdicción civil y criminal, siendo la autoridad inmediatamente inferior a los corregidores de indios, por encima de los alcaldes ordinarios. Por último, el maestre de campo hacía referencia a un oficio perteneciente a la milicia local.

48 A partir de la confrontación de la Probanza de méritos y servicios de don Francisco Aymoro con diversa información procedente de las Escrituras Públicas de la ciudad de La Plata, Ana María Presta da cuenta de los hiatos que presenta su supuesto linaje genealógico, influenciado con seguridad por las cartas de hidalguía castellanas. Presta, Ana M., "Los Aymoro, caciques de los yamparas. ¿Un linaje ancestral o una construcción colonial toledana?”, Conferencia pronunciada en La Paz, el 16 de noviembre, con motivo de su ingreso a la Academia Boliviana de Historia, 2011.

49 Para un análisis de los testamentos de don Juan Colque Guarache y de don Francisco Aymoro, véase respectivamente Abercrombie, 1998: 268. Presta, 2008: 54-56; $2011 \mathrm{~b}$.

50 "Segunda Información hecha por don Juan Colque Guarache, cacique principal de los quillacas [1576-1577]”. Espinoza Soriano, 1981: 253.

51 "Probanza de méritos y servicios de don Fernando Ayavire y Velasco, cacique gobernador del repartimiento de Sacaca", Memorial de Charcas, 1986: 71.

52 AGI, Charcas, leg. 44, Probanza de Francisco Aymoro, cacique gobernador de los yamparaes, f. $10 \mathrm{v}$.

53 "Probanza de don Fernando Ayra de Ariutu, cacique y gobernador de Pocoata" [1638], Platt, Bouysse-Cassagne y Harris, 2006: 733. 
Decían ser buenos cristianos, temerosos de dios y de los sacerdotes:

...buen cristiano y temeroso de dios [...] le an hecho mucha merced ansi los señores obispos como los demas prelados. Don Fernando Ayavire y Velasco [1583 ${ }^{54}$. ...muy buen cristiano temeroso de dios i mui zeloso de su servicio y como tal a puesto $[\ldots]$ mucha diligencia i tiene gran cuidado de hazer y que hagan suficiente doctrina y todo buen enseñamiento de nuestra santa fe católica. Don Francisco Aymoro [1586] ${ }^{55}$.

...buen cristiano, temeroso de dios. Don Fernando Ayra de Arriutu [1638] ${ }^{56}$.

También eran arduos combatientes de las borracheras e idolatrías de sus indios:

... a andado y anda personalmente por las rancherias de la villa de Potosí evitando las borracheras y otros malos vicios. Don Fernando Ayavire y Velasco [1583] ${ }^{57}$. ...poniendo mucha diligencia para quitarlas borracheras e los demas vicios i pecados antiguos. Don Francisco Aymoro [1586 ${ }^{58}$.

...no consintiendo borracheras, amancebamientos y otros pecados públicos. Don Fernando Ayra de Arriutu [1638 $]^{59}$.

Incluso, ostentaron su catolicismo mediante la construcción de iglesias en sus pueblos y su decoración con adornos y cuadros que los incluían como fieles servidores de dios y de Su Majestad, como es el caso don Fernando Ayra de Arriutu, quien «(...) en la iglesia ha hecho y puesto muchos ornamentos y un retablo...fomentando algunas limosnas». El ejemplo quizás más acabado de estos miembros de la élite indígena de Charcas colonial lo representa don Juan Colque Guarache, quien, según la conocida cita del propietario de ingenios Luis Capoche,

Ha oído gramática en el colegio de la Compañía de Jesús y anda vestido a nuestro modo, con mucha seda. No se hallan bien con él los indios, así por el

\footnotetext{
54 "Probanza de méritos y servicios de don Fernando Ayavire y Velasco, cacique gobernador del repartimiento de Sacaca", Memorial de Charcas, 1986: 70-71.

55 AGI, Charcas, leg. 44, Probanza de Francisco Aymoro, cacique gobernador de los yamparaes, f. $10 \mathrm{r}$.

56 "Probanza de don Fernando Ayra de Ariutu, cacique y gobernador de Pocoata" [1638], Platt, Bouysse-Cassagne y Harris, 2006: 733.

57 "Probanza de méritos y servicios de don Fernando Ayavire y Velasco, cacique gobernador del repartimiento de Sacaca", Memorial de Charcas, 1986: 73.

58 AGI, Charcas, leg. 44, Probanza de Francisco Aymoro, cacique gobernador de los yamparaes, f. $10 \mathrm{v}$.

59 "Probanza de don Fernando Ayra de Ariutu, cacique y gobernador de Pocoata" [1638], Platt, Bouysse-Cassagne y Harris, 2006: 73.
} 
traje... [y porque] no entiende el estilo y usanza y costumbres de su gobierno ni trata a los indios con afabilidad ${ }^{60}$.

La redacción de cada una de sus probanzas de méritos y servicios remite a demandas de merced real -no siempre otorgadas-y un contexto particulares. El cargo de capitán de mita (don Fernando Ayavire y Velasco); un escudo de armas y la cesión de una encomienda (don Fernando Ayra de Arriutu); o bien extensas peticiones como las de don Juan Ayavire y Coysara quien solicitaba tributos e indios vacos, la confirmación de los oficios de cacique principal del repartimiento de Sacaca y de alcalde mayor de los naturales de la Provincia de Charcas, la facultad de acompañarse de dos esclavos con espadas, Cédula Real para que se le confirmen y dejen exhibir las armas -espada y daga- de sus antepasados, un hábito de la orden de Santiago y la merced de la administración de los bienes de comunidad del Partido de Chayanta con el quinto de multiplico del maíz, ganado y chuño. Para lograrlo, las probanzas de méritos y servicios incluían interrogatorios cuidadosamente construidos, de extensión variable, con preguntas largas, detalladas y conducentes, que de modo deliberado llevaban al testigo a responder afirmativamente ${ }^{61}$.

De acuerdo al modelo notarial y nobiliario peninsular, las probanzas de méritos indígenas se estructuraron en torno a un relato genealógico, registrando linajes cacicales cuya profundidad temporal es difícil de contrastar. El primer interrogante que se impuso luego de una lectura de conjunto apunta al concepto mismo de genealogía que estructuraba las probanzas de méritos cacicales; es decir, ¿existía una memoria genealógica andina? ¿Podemos pensar que estos registros del pasado en formato e idioma castellano seguían un esquema previo, local, de conservación de la memoria en torno a las descendencias de líderes fundadores de linajes gobernantes ${ }^{62}$ ? $\mathrm{O}$ bien, ¿fueron producto de la sociedad andino colonial postoledana ${ }^{63}$ ? Entre las probanzas de

\footnotetext{
60 Capoche, 1959 [1585]: 137.

61 Esta técnica es advertida en la Instrucción y memorial para escrivanos y juezes ejecutores de Bartolomé de Carvajal, quien describía el modo en que los testigos, a quienes se leían preguntas que comenzaban con elementos difíciles de probar mientras que finalizaban con hechos conocidos y altamente probables, sólo retenían la última parte, respondiendo afirmativamente. Burns, 2010: 198, nota 47.

62 La genealogía ha sido rescatada recientemente para el análisis dinástico incaico por Catherine Julien, quien sugiere que la historia de los incas contenida en las crónicas hispanas, estructurada en torno al recuento genealógico del linaje de Manco Inca, no sólo refleja un modelo occidental de aproximación histórica sino que podría estar basada en fuentes o géneros incaicos. Julien, 2000.

63 Susan Ramírez llama la atención sobre aquellas genealogías indígenas que, en época colonial, codificaron tradiciones orales, repitiendo nombres de líderes étnicos a lo largo de
} 
méritos publicadas de importantes líderes de Charcas colonial, sólo dos de ellas, distantes en el tiempo, abordaron el pasado familiar del interesado mediante el uso del concepto de «casa» o linaje ${ }^{64}$. El término casa evocaba en el vocabulario de la época la práctica nobiliaria peninsular de pertenencia a un linaje, es decir, al conjunto de descendientes por vía masculina que conformaban una familia extensa. Según el vocabulario de Cobarruvias, «(...) porque las tales [moradas y casas] son en los propios solares de donde traen origen, vinieron a llamarse los mesmos linajes, casas, como la casa de los Mendozas, Manriques, Toledos, Guzmanes, $\& \mathrm{c} \gg{ }^{65}$.

En la sociedad castellana, el individuo obtenía su identidad social en tanto miembro de un grupo parental amplio, el cual situaba a sus integrantes, según el estatus de cada uno, en el conjunto de las relaciones sociales al mismo tiempo que sustentaba el control sobre la tierra y la mano de obra ${ }^{66}$. En Castilla, las casas o linajes nobiliarios impusieron el mayorazgo como régimen patrimonial y sucesorio de la propiedad señorial a partir de mediados del siglo XIV, comprendiendo la totalidad de los bienes y derechos de un determinado patrimonio. ¿Es esto mismo lo que sucedía en la sociedad andina prehispánica y, luego, colonial?

En el interrogatorio incluido en la primera probanza de méritos de don Juan Colque Guarache, capitán general de los mitayos quillacas y asanaques, en 1575, la pregunta decimoséptima conducía a los testigos hacia el concepto de casa para enfatizar el estatus de su linaje:

17. Item. Si saben, etc. que el dicho Guarache fue christiano, natural del pueblo [de] quillaca, del ayllo Malcoca, que en lengua española quiere decir generacion de señores y fue de la casa de Guarache ${ }^{67}$.

\footnotetext{
generaciones, y cuya explicación se encuentra más allá de la conformación y perduración de un linaje en el sentido peninsular del término. Ramírez, 2006.

64 Encontramos también su mención en informaciones de filiación de dos aspirantes a jilaqata o líderes de ayllu, pertenecientes al repartimiento de Macha, a comienzos del siglo XVII. Ver: Platt, 1987: 71. Platt Bouysse-Cassagne y Harris, 2006: 663. Jurado, 2013.

65 Cobarruvias, 1943 [1611]: 107.

66 Chacón Jiménez y Hernández Franco, 1992: 7-14. Rodríguez Sánchez, 1992. Pérez, 1996.

67 [El subrayado es nuestro]. Espinoza Soriano, 1981: 239. Una de las versiones de la probanza de méritos y servicios de don Juan Colque Guarache se encuentra en AGI, Quito, leg. 45, y ha sido publicada parcialmente por Waldemar Espinoza Soriano. Otra versión fue encontrada por Thomas Abercrombie en el Archivo del Tribunal de Poopó (Estado Plurinacional de Bolivia).
} 
El concepto apuntaba, de acuerdo a la mentalidad jerárquica y señorial del escribano y asesores legales intervinientes, a la inclusión de Colque Guarache en un linaje de señores, «los Colque Guarache» parafraseando la expresión de Cobarruvias, de acuerdo a la práctica nobiliaria europea. Los testigos, tres líderes indígenas de la región, confirmaron la pertenencia de Colque Guarache al ayllu Malcoca pero evadieron completamente la referencia a la supuesta casa -como si no valoraran su existencia-. El modelo provisto por el formulismo notarial y el esquema usual para las probanzas de méritos de españoles no se ajustaron a la realidad andina que se pretendía interpelar, por lo cual los testigos indígenas guardaron silencio frente a un concepto que, en 1575, no encontraba asidero en su mentalidad.

El término vuelve a presentarse sesenta y tres años más tarde, en la probanza de méritos de don Fernando Ayra de Arriutu, cacique gobernador del repartimiento de Pocoata. Su notario o asesor legal incluyó en el interrogatorio dos preguntas muy sugerentes; una de ellas encaminaba a los testigos a confirmar que «fue hijo legitimo de don Fernando Capax, descendiente por línea directa de varón de la casa de Capax Localarama»y, más adelante, profundizaba la cuestión de su linaje al solicitar dijeran que «es descendiente de parte de madre de la casa de Anco Tutumpi Ayra Canchi». ${ }^{68}$ Muchas cosas habían cambiado en el Virreinato del Perú desde mediados de la década de 1570, cuando la probanza de méritos de Colque Guarache pretendía asimilar la práctica de sucesión y patrimonial de los señores andinos a la de la casa de la sociedad nobiliaria europea. Sin embargo, en 1638, la probanza de méritos de Arriutu continuaba ajustada a la reglamentación y las formas de contrastación de la evidencia de fines del siglo XVI. En esta oportunidad, los testigos indígenas presentados, líderes de distintas jurisdicciones, no desconocieron el concepto de casa y confirmaron las palabras exactas que se incluyeron en el interrogatorio, sin agregar dato alguno. De acuerdo a esta evidencia, ¿deberíamos aceptar sin más la existencia de linajes o casas similares a las de la sociedad peninsular en las sociedades aymaras prehispánicas y coloniales? ¿Es ese concepto la traducción hispana, realizada por los notarios, de una práctica local similar a la castellana? ¿Trasladaríamos conceptos como primogenitura, monogamia, líneas rectas de varón, legitimidad y bastardía, contenidos también en las probanzas de méritos y servicios cacicales?

68 El subrayado es nuestro. La probanza de méritos de don Fernando Ayra de Arriutu se encuentra en AGI, Charcas, leg. 56, y ha sido publicada por Platt, Bouysse-Cassagne y Harris, 2006: 721-755. 
Luego de leer en detalle y comparativamente las probanzas de méritos de Colque Guarache, Ayavire y Velasco ${ }^{69}$, Aymoro $^{70}$, Ayra de Arriutu ${ }^{71}$ y Fernández Guarache ${ }^{72}$, se impone en el análisis al menos la perplejidad: ¿cómo avanzar entre tantos nombres, datos y preeminencias individuales e incontrastables pero, al mismo tiempo, repetitivos y previstos desde una mirada de conjunto? Aún adoptando la precaución metodológica anunciada por Mario Graña acerca de leer las probanzas de méritos indígenas fuera de la dicotomía verdad-mentira para acercarnos a la idea de un diálogo entre lo real y lo imaginario $^{73}$, trascender las marcas político-sociales coloniales de dichos documentos es un desafío metodológico y hermenéutico de envergadura.

De la comparación textual de los interrogatorios propuestos en las probanzas de méritos mencionadas, efectuadas entre 1574 y 1719 , se impone una conclusión: las similitudes apuntan al contenido mismo. Todas ellas pertenecen al período de mayor influencia de las ordenanzas toledanas y de amplia difusión de los conceptos europeos de primogenitura, herencia masculina y modelos genealógicos como garantía de legitimidad. A ello debemos sumar los filtros del idioma y de la cultura, los formulismos notariales y el rol de notarios y asesores legales al inducir y ajustar los deseos y palabras de su cliente en un lenguaje jurídico capaz de ser comprendido en un contexto judicial. Todo ello debió impactar sin duda en el contenido de las probanzas de méritos, ejerciendo notable influencia en la reconstrucción de la visión del mundo y de la memoria histórica andinas.

Con diferencias diacrónicas entre las probanzas de Colque Guarache [1574-75; 1576-77] y Avavire [1583-84] por un lado y las de Ayra de Arriutu [1638] y Fernández Guarache [1719] por el otro, se imponen en todas ellas

$69 \mathrm{Su}$ probanza de méritos se encuentra inserta en el Memorial de Charcas. Trascripción paleográfica de Margarita Suárez, manuscrito 1986.

70 Probanza de Francisco Aymoro, cacique gobernador de los yamparaes, AGI, Charcas, leg. 44.

71 Probanza de don Fernando Ayra de Arriuto, cacique y gobernador de Pocoata, AGI, Charcas, leg. 56. Provisión Real concediendo un escudo de armas a Francisco Ayra de Arriuto (1640), Archivo y Biblioteca Nacional de Bolivia, Sucre (ABNB), Correspondencia de la Audiencia de Charcas, leg. 1463. Una transcripción de su Probanza se encuentra en Platt, Bouysse-Cassagne y Harris, 2006, 721-755.

72 La versión de la probanza de méritos de don José Fernández Guarache ha sido hallada y transcripta por Roberto Choque, 2003: 51-53. Fragmentos de esta probanza se encuentran insertos en el Archivo de La Paz (ALP), Provincia Pacajes (PP), Juzgado años 1730-1749, caja 11, junto con algunos resúmenes de la Información con testigos hecha por su padre, don Pedro Fernández Guarache, ante el corregidor don Antonio Baca Dávila. Agradezco al Dr. Ariel Morrone por brindarme esta información.

73 Graña, 2000: 554. 
semejanzas. La confección de la escritura y la cuidadosa implementación del protocolo legal llevan a pensar en un conjunto de consejeros letrados y escribientes conocedores del sistema de presentación judicial, que asesoraba a los líderes indígenas sobre los modos de ajustar los parentescos andinos en términos occidentales y de exaltar su estirpe en las probanzas de méritos y servicios. Los notarios y asesores legales inmiscuidos parecen haber recurrido a las recomendaciones de tratados como el de Monterroso o González de Torneo acerca de los elementos centrales de toda probanza de hidalguía, tales como el uso de preeminencias de hidalgos, la ocupación de cargos u oficios importantes en el gobierno, su llamamiento a guerras, su uso de armas y caballos y su reputación de hidalgos como "pública voz y fama y común opinión» y «público y notorio».

Las similitudes que presentan los linajes cacicales son especialmente evidentes en la repetición de lugares comunes o hitos discursivos. Todos ellos acreditaban parientes que fueron hábiles (y dóciles) mediadores con el Tawantinsuyu, atributo propio de la autoridad andina garante de la relación con las divinidades y de la intermediación entre «sayas» y grupos. En las probanzas de méritos analizadas, los linajes fueron respetados por el Inca, cuya intromisión sirvió para reafirmar los poderes y legitimidades previos:

...fueron señores de duho antes y en tiempo del inga y después acá que era la insignia de los caballeros [...] y así lo fueron sus padres y abuelos por le venir el dicho cacicazgo por justos y derechos títulos de línea reta de Huno Mallco, que quiere decir señor de Sava que es como duques, condes, marqueses en los reinos de España. Don Juan Colque Guarache [1575] ${ }^{74}$.

...fueron señores de duo y antes del ynga y después acá que hera las insinias de los cavalleros y como tales fueron avidos y respetados libres de tributo ni servidumbre [...] por le venir el dicho cacicazgo por justo y derechos títulos de línea recta de Huno Malco que quiere decir señor de Sava en los reynos de España [...] dio la obediencia a el ynga, el qual le confirmó lo que antes tenia. Don Fernando Ayavire y Velasco $[1583]^{75}$.

...y se an susedido unos a otros en el casicasgo y gobierno de este pueblo de padres a hijos desde la jentilidad y su prosapia antigua sin que se entremetiese en el estraño ninguno. Don José Fernández Guarache [1719] ${ }^{76}$.

\footnotetext{
74 "Primera Información hecha por don Juan Colque Guarache [1575]", Espinoza Soriano, 1981: 237.

75 "Probanza de méritos y servicios de don Fernando Ayavire y Velasco, cacique gobernador del repartimiento de Sacaca", Memorial de Charcas, 1986: 65-66.

76 ALP, PP, Juzgado 1730-1749, caja 11, f. 3v. Agradezco al Dr. Ariel Morrone por haberme permitido acceder a la transcripción paleográfica de este documento.
} 
Esta transición no problemática, planteada especialmente en las probanzas de méritos de Colque Guarache y Ayavire, constituye un espejo de la alianza que se pretende continuar con la consolidada administración colonial y representa un diálogo con las averiguaciones que, desde 1570 y hasta 1582, realizaron sucesivamente los Virreyes Toledo y Enríquez sobre la tiranía de los incas y la de sus supuestamente designados kurakas ${ }^{77}$. Las frases señaladas, más que indicar la perduración de una línea sucesoria que se remonta al período preincaico, deben remitirnos al contexto específico de su producción. Así, las probanzas de méritos cacicales modificaron en buena medida las tradiciones orales andinas, dejando la impresión de la existencia de una sucesión hereditaria basada en la primogenitura, la patrilocalidad y la legitimidad atadas a un matrimonio monogámico. Contenida en documentos persuasivos y esquematizados según el carácter probatorio de la sociedad peninsular, la memoria andina evocada en probanzas de méritos debió convertir su discurso en uno inteligible para el destinatario, a fin de obtener su cometido.

Asimismo, los antepasados de los kurakas pleitistas ocuparon al parecer los más principales roles de gobierno en el Tawantinsuyu:
...era del consejo de guerra del dicho inga Manco Capac. Don Juan Colque Gua- rache $[1575]^{78}$.
...los dichos yngas (...) le ocupavan en capitanías y conquista allende del govier- no. Don Fernando Ayavire y Velasco $[\mathbf{1 5 8 3}]^{79}$.
... estava nombrado por el Inga por governador de toda esta provincia de los Char- cas y por cacique principal de dicho repartimiento de los iamparaes. Don Francis- co Aymoro [1586 ${ }^{80}$.
... [el Inca Huayna Capac] lo hiso governador de los yndios de todas las provincias que corren desde Vilcanota hasta Chile. Don José Fernández Guarache [1719] ${ }^{81}$.

La contrastación de la documentación dibuja así un pasado de superposición de líderes en el mismo cargo, tales como gobernadores de toda la provincia de los Charcas (los antepasados de Aymoro y de Fernández Guarache), señores vinculados al sistema decimal - de hunu, en la probanza de méritos

77 Carta del Virrey Toledo a S.M., Cuzco, 25 Marzo 1571, Levillier, 1924, vol. III: 443. Probanza del gobierno y costumbres de los ingas por orden del Virrey Enríquez, AGI, Lima, leg. 30.

78 "Primera Información hecha por don Juan Colque Guarache [1575]", Espinoza Soriano, 1981: 238 .

79 "Probanza de méritos y servicios de don Fernando Ayavire y Velasco, cacique gobernador del repartimiento de Sacaca", Memorial de Charcas, 1986: 66.

80 AGI, Charcas, leg. 44, Probanza de Francisco Aymoro, cacique gobernador de los yamparaes, f. $8 \mathrm{v}$.

${ }^{81}$ ALP, PP, Juzgado 1730-1749, caja 11, f. 3r. 
de Ayavire y de Colque Guarache; y señor de dos hunu, en la probanza de méritos de Arriutu-, integrante del consejo de guerra del Inca (en la probanza de méritos de Colque Guarache) o cargos de capitanía en las batallas (en la probanza de méritos de Ayavire), convocados a guerras por su valentía, distinción y liderazgo. Si bien no es información contenida en una probanza de méritos, sabemos por la Visita de Chucuito que en 1567 existía el recuerdo entre los lupaqa de que su líder Apo Cari había sido «(...) gran señor como segunda persona del Inga y mandaba desde el Cusco hasta Chile» ${ }^{82}$. Asimismo, Mercedes del Río encuentra que un señor de Charcas, conocido como Inga Achata, se recordaba como «(...) governador que fue por Ynga Guayna Capac desde Vilcanota e Omasuyu y Urcosuyu hasta las provincias de Chile» ${ }^{83}$. Posiblemente estemos ante una superposición de cargos detentados por los diferentes linajes provinciales producto del afán de las probanzas de méritos de apropiarse de un atributo de poder valorado por los tratados nobiliarios peninsulares: el uso de «cargos u oficios en la república».

Cada uno de los integrantes de los supuestos linajes de las distintas probanzas de méritos compartía atributos virtuosos. Todos ellos se delinearon como valientes guerreros, líderes máximos, hábiles mediadores que reunían fuerza, virilidad y coraje, presentando los mismos atributos que, según crónicas hispanas y mitos orales, poseía el Inca en tanto arquetipo primordial de la autoridad en los Andes. El Inca, al igual que otras autoridades andinas, se consideraba sagrado; esto permitía una asociación entre divinidad y gobernante que lo hacía ver como fuerza animadora, ordenadora y sustentadora del mundo. El noveno Inca, Pachakuti, al igual que el primero, Manco Capac, repetían en sus ciclos míticos una figura arquetípica que marcaba los patrones del gobernante andino; ambos proveyeron un modelo ejemplar con el cual la población y los kurakas relacionaban la autoridad ${ }^{84}$.Asimismo, según las probanzas de méritos, el Inca brindó generosamente a los antiguos líderes, parientes de los litigantes, similares objetos de prestigio, símbolos incaicos de autoridad y estatus, que visibilizaban su jerarquía, al disponer de andas, indios de servicio o yanas, camisetas de oro y plata, vasos y ropa fina de cumbi. Así,

...insignias de cavallero, tres camisetas, la una de chapería de plata y otra de chapería de oro y otra de piedras preciosas que llaman mollo [...] [el Inca] le dio andas. Don Juan Colque Guarache $[\mathbf{1 5 7 5}]^{85}$.

\footnotetext{
82 Diez de San Miguel, 1964 [1567]: 106.

83 Del Río, 1990: 80.

84 Pease, 1989: 30-31.

85 "Primera Información hecha por don Juan Colque Guarache [1575]", Espinoza Soriano, 1981: 237.
} 
...los yngas le dieron ansimismo yncinias de cavallero, dos camisetas la una de chapería de oro y la otra chapería de plata y mucha ropa fine de cunbe y cocos de plata y oro $[\ldots]$ fue señor de lanpa ques a manera de litera y traía quitasol de plumerías. Don Fernando Ayavire y Velasco $[1583]^{86}$.

...como tal governador [del Inca] andava en andas. Don Francisco Aymoro $[1586]^{87}$.

...el dicho Inca [Guaina Capax] le honró mucho y le dio una camiseta de roeles de oro. Don Fernando Ayra de Ariutu [1638 $]^{88}$.

...por el amor que tubo el Ynga Maita Capax rey natural que fue de este reyno a los desendientes del dicho Apo Guarache dio una camiseta de su vestir. José Fernández Guarache $[1719]^{89}$.

Estos objetos son bien conocidos por todos aquellos que estudian las formas que adoptan las relaciones de poder en las sociedades andinas ${ }^{90}$. En especial, las andas o literas, acompañadas por hombres encargados de su transporte, constituyen uno de los emblemas o insignias que identifican a quienes ejercieron la autoridad en los Andes ${ }^{91}$. Se destacan, en las probanzas de méritos analizadas, el linaje de Ayavire, que presenta andas con quitasol de plumas -otro elemento que conforma el conjunto significante de la autoridady el linaje de Arriutu, cuyo estatus era indicado por la calidad del material, oro.

Arriutu y Fernández Guarache adicionaban a los privilegios anteriores el haber recibido el don del parentesco, al casarse sus antepasados con miembros del linaje del Inca. Por ejemplo,

...[el Inca] le casó con una de sus hijas llamada Payco Chinbo. Fernando Ayra de Arriuto [1638 ${ }^{92}$.

\footnotetext{
86 "Probanza de méritos y servicios de don Fernando Ayavire y Velasco, cacique gobernador del repartimiento de Sacaca", Memorial de Charcas, 1986: 66.

87 AGI, Charcas, leg. 44, Probanza de Francisco Aymoro, cacique gobernador de los yamparaes, f. $8 \mathrm{v}$.

88 "Probanza de don Fernando Ayra de Ariutu, cacique y gobernador de Pocoata" [1638], Platt, Bouysse-Cassagne y Harris, 2006: 730.

89 ALP, PP, Juzgado 1730-1749, caja 11, f. 3v.

90 Murra, 1975. Martínez Cereceda, 1995. Pärssinen, 2003: 141-144.

$91 \mathrm{Al}$ momento en el que los interesados presentaron sus probanzas de méritos y servicios, el uso de las andas estaba prohibido, no sólo de forma expresa y general, como en las Ordenanzas del Dr. Cuenca (1566), sino también de forma más circunscrita a ciertos kurakas, como lo denuncian los propios lideres indígenas en el Memorial de Charcas. Para un análisis en detalle de las andas como integrante de un conjunto significante de la autoridad, véase Martínez Cereceda, 1995.

92 "Probanza de don Fernando Ayra de Ariutu, cacique y gobernador de Pocoata" [1638], Platt, Bouysse-Cassagne y Harris, 2006: 730.
} 
...el parentesco inmidiato que tubo el Ynga Guayna Capax con el dicho Chalco Yupanqui. José Fernández Guarache [1719] ${ }^{93}$.

Es sugerente que el entronque parental de un linaje local con aquel de los incas haya sido recordado y registrado sólo en aquellas probanzas de méritos realizadas con posterioridad a la caída de la facción incaica que oponía resistencia desde Vilcabamba. La recuperación de la figura del Inca que se generaliza en el siglo XVII permitía reforzar legitimidades simbólicas, potenciada en el siglo XVIII, como es el caso de Fernández Guarache quien ha sido propuesto como ejemplo paradigmático de la cultura «neo-inca» ${ }^{94}$.

Las «preeminencias de caballeros», como son presentadas a ojos españoles, sólo podían estar en manos de hombres de calidad, quienes también recibieron nuevos nombres o títulos, como el de «Inca». El grupo parental de Arriutu sobresale por la abundancia: no sólo su pariente paterno recibió el de «Capax» ${ }^{95}$ sino que en su rama materna figura el de «Anco Tutumpi» y sus sujetos se renombraron como «Caracara» ${ }^{96}$. De conjunto, la probanza de méritos de don Fernando Ayra de Arriutu [1638] presenta rasgos peculiares que ameritan una lectura crítica y problematizadora. En ella, su linaje se delinea como el primer caso -luego emulado en la probanza de méritos de don José Fernández Guarache de 1719- en el que la preeminencia de la autoridad local es tal que el orden de reciprocidades descrito se ve trastocado. Los dones ofrecidos por el líder étnico al Inca son previos, puesto que su antepasado, Localarama, se presentó al Inca como embajador y «(...) dio noticia al dicho Inca de las cuatro provincias de Collasuio, Antesuio, Condesuio y Chinchaysuio y de la calidad de las tierras, que le dio un mapa tejido en ropa de cumbi en la lengua de los indios la llaman carpatira ${ }^{97}$.

El mismo orden sucede con las insignias de preeminencia. Las restantes probanzas de méritos asimilaron las andas y literas con bienes y distinciones que otorgaba el Inca; sin embargo, para el recuento de Arriutu, las andas que usaba su antepasado, Ayra Canche, constituían un atributo previo a cualquier

\footnotetext{
93 ALP, PP, Juzgado, 1730-1749, caja 11, f. 3r.

94 Morrone, 2010: 217.

95 Según Julien, el término «capac» alude al estatus hereditario concentrado en la línea dinástica inca de los descendientes de Manco Capac y su hermana-esposa y, asimismo, a un título que denotaba a un gobernante local hereditario. Julien, 2000: 23-48.

96 Qaraqara es como se conoce a la entidad política que se extendía desde el norte de Potosí hasta el río Pilcomayo, en la frontera con la entidad política Chicha (actual Departamento de Tarija, Estado Plurinacional de Bolivia).

97 Probanza de don Fernando Ayra de Arriutu [1638], Platt, Bouysse-Cassagne y Harris, 2006: 728 .
} 
don del Inca pues aquel «(...) fue tan poderoso, rico y respetado que no se preciaba en menos de que lo trajesen en andas de oro» ${ }^{98}$. Sus hazañas militares también fueron previas al Tawantinsuyu pues se afirmaba que dicho personaje había edificado fortalezas y había incorporado territorios bajo su dominio, extendiéndolo hasta el límite con los indios Chichas y la zona de Pilaya y Paspaya, en torno al río Caine/Grande y el río Pilcomayo. En reconocimiento de su prestigio, «(...) el primer Inca Tupangui [Pachakuti] hizo mucho caso y estimación y le envió un embajador llamándole y honrándole con el apellido Anco Tutumpi que quiere decir flor blanca que brota como quien dice que no tenía otro su igual ${ }^{99}$.

Esta inversión del sistema de reciprocidades, que elevaba a Ayra Canche al estatus reservado en la memoria colectiva al Inca, vuelve a aparecer en la probanza de méritos de don José Fernández Guarache, cacique gobernador del repartimiento de Jesús de Machaca, de 1719. Según su probanza, su antepasado Apo Guarachi aparece como señor «(...) desde el Desaguadero hasta los contornos de Potosí y Chuquisaca» previo al dominio de los incas, con quienes inicia el juego de reciprocidades al enviar a dos de sus hijos «(...) a la aparición del primer Inga Manco Capac en Paucartambo en señal de obediencia» ${ }^{100}$. Nuevamente, el dominio de un solo líder aymara sobre una jurisdicción extensa y abarcativa de los Andes Centro-Sur es un dato reiterado y disputado en la memoria de los testigos indígenas coloniales, cualquiera fuera su etnicidad.

Es este sólo un ejemplo de las discordancias que surgen al concordar las versiones del pasado que se fijaban por escrito en probanzas de méritos pertenecientes a distintos grupos y épocas históricas, considerando este tipo de documentación como fuente productora de datos históricos y evaluando sólo el núcleo de credibilidad a extraer. Nos enfrentamos, en realidad, con el registro colonial de tradiciones orales fluidas, maleables y en disputa. El recuerdo en los Andes y la historia individual, genealógica y colectiva se ordenaban a través de categorías ejemplares, conocidas a través de fórmulas orales y míticas, mantenidas en numerosos contextos rituales y de conservación de la memoria ${ }^{101}$. Estos acontecimientos y arquetipos primordiales, reconocibles tras aquellos supuestos parientes preincaicos e incaicos de las probanzas de méritos, sólo pueden haber encontrado su ordenamiento lineal y su función

98 Probanza de don Fernando Ayra de Arriutu [1638], Platt, Bouysse-Cassagne y Harris, 2006: 730 .

99 Idem.

100 Choque Canqui, 2003: 51-52.

101 Pease, 1989: 29. 
«histórica»y genealógica en la codificación realizada por los notarios y los líderes indígenas, de acuerdo a la reglamentación colonial.

La importancia que dio el sistema legal español al pasado prehispánico abrió un período fecundo para la actualización y acomodamiento de los recuerdos, para la escritura de visiones contrapuestas de la historia, idealizaciones, silencios y discontinuidades. Los procesos vinculados al recuerdo y los usos de la memoria han recibido la atención de numerosos investigadores desde que Maurice Halbawchs resaltara su carácter de memoria histórica, reconstruida a partir de los imperativos del presente y vulnerable a usos y manipulaciones ${ }^{102}$. Memorias colectivas, aún cuando los recuerdos parezcan estrictamente individuales, memorias complejas, dinámicas y procesuales, mezcla inexorable de experiencias pasadas y presentes, asoman también al analizar los recuentos genealógicos kurakales contenidos en las probanzas de méritos. En ellas, los kurakas se ubicaron en la juntura de una doble memoria: una memoria grupal, étnica, que recordaba las hazañas de guerreros y capitanes ejemplares, y una memoria genealógica que pretendía descender de estos héroes arquetípicos étnicos, al heredar su prestigio de aquellos líderes fundadores $^{103}$. Se transformaron de esta manera antepasados míticos en seres concretos, parientes directos de líderes individuales e insertos en una genealogía precisa, aún a costa de la pérdida de su significado tradicional. Dicha genealogía individual, perteneciente a un líder indígena en particular, brindaba un parentesco directo - cual Inca- con las divinidades, una ascendencia hacia lo sagrado, y se convertía en la justificación legitimadora del poder ${ }^{104}$.

Las probanzas de méritos de algunos kurakas de Charcas colonial se revelan, ante todo, como construcciones complejas; el registro de la memoria que realizan encapsula por lo menos dos períodos de tiempo: el tiempo de lo que se recuerda y el tiempo en el que fueron registradas. Al igual que en las crónicas hispanas, se da en ellas un proceso de composición, cuya autoría es compleja y refleja una perspectiva del pasado situada en determinado momento y según determinados autores ${ }^{105}$. Las probanzas de méritos de las antiguas jurisdicciones del Collao y de Charcas analizadas más arriba presentan una dominación incaica pacífica, ordenada, negociada y de respeto de las estruc-

102 La noción de memoria se ha convertido en un termino polisémico y fluido, aplicado a distintos fenómenos como recuerdos, conmemoraciones, archivos y monumentos, invención de tradiciones, olvidos y usos del pasado. Los estudios pioneros de Maurice Halbawchs han dado el puntapié inicial y han sido retomados y cuestionados por numerosos investigadores. Véase, entre otros, Halbawchs, 1968. Nora, 1984. Briones, 1994.

103 Saignes, 1987: 158.

104 Ramírez, 2006: 17.

105 Julien, 2000: 14. 
turas étnicas preexistentes. Sin embargo, la dominación no fue igual en toda la región andina, e, inclusive, el Tawantinsuyu no era una estructura monolítica, primando las alianzas de determinadas facciones de la élite incaica con ciertos grupos de los ayllus a sujetar. Es sabido que los collas, lupaqas y pacajes del Collao impusieron resistencia desde sus pukaraes al avance incaico y que sólo luego de ser derrotados y sus líderes castigados, fueron sojuzgados; lo mismo ocurrió con los carangas, de manera tal que la antigua provincia de los Charcas también debió conquistarse por las armas ${ }^{106}$. Sin embargo, este recuerdo se ha silenciado en las probanzas de méritos y los hechos conflictivos se borraron del pasado en función de las necesidades de un presente armonioso. Así, este proceso de idealización del pasado se refleja en la construcción de un pasado homogéneo y con pretensiones de autenticidad.

Se ha resaltado previamente al analizar el caso de Arriutu cómo, a pesar de las similitudes, las probanzas de méritos cacicales no pueden ser homologadas. Los discursos que contienen, la memoria rescatada, los silencios y omisiones, las jerarquías y preeminencias están atados a los avatares de la facción que emite, acompaña y sostiene el relato. El recuento genealógico de la probanza de méritos es una representación del pasado, una composición creada en un momento y por un autor o autores específicos. Versiones distintas del pasado fueron mantenidas por grupos rivales, cuya credibilidad social estuvo vinculada con los tipos de fuentes de autoridad utilizadas para sostener el relato. Es sabido que las distintas panaca que conformaban la élite incaica conservaban versiones diferenciadas del pasado, ligadas a su fundador, tras una memoria transmitida oralmente y que podía contradecir la de grupos rivales. Del mismo modo, estudios contemporáneos han demostrado que en ciertas regiones de los Andes los memoristas de la comunidad, pertenecientes a lo largo de generaciones a grupos particulares, conservan las tradiciones locales e, inclusive, que distintos grupos se especializan en la preservación de recuerdos específicos ${ }^{107}$.

Así, el pensamiento histórico colonial contenido en las probanzas de méritos y servicios kurakales, codificado en narraciones cronológicas enfocadas en acciones individuales especialmente heroicas, lejos de representar la historia del grupo étnico en su totalidad refleja la interpretación histórica de la facción que respaldaba la presentación del interesado. La necesidad de atestiguar sus méritos y servicios obligaba a los indígenas litigantes a internarse en redes sociales eficaces que fundamentaran sus pretensiones, incluyendo a

106 Rowe, 1985.

107 Rappaport, 1994. 
líderes indígenas del mismo grupo y/o de otras regiones, hasta clérigos y funcionarios españoles. Podríamos asomarnos al grupo social que sustentaba a los litigantes reconstruyendo las redes de testigos que confirmaron sus versiones genealógicas. Llaman la atención los casos en los que las probanzas de méritos y servicios e informaciones de filiación presentaron testigos en su mayoría ajenos a la entidad socio-política y parcialidad del peticionario. Fue el caso, por ejemplo, de la probanza de méritos de don Fernando Ayra de Arriutu [1638], cacique gobernador del repartimiento de Pocoata, quien, deseoso de confirmar su pertenencia por vía materna a un prestigioso linaje de Macha, presentó trece testigos, de los cuales sólo seis eran indígenas y sólo uno del mencionado pueblo. Claramente, Arriutu evitó convocar a un número importante de integrantes del repartimiento de Macha, entre los cuales la memoria de su supuesto antepasado permanecía activa y en disputa ${ }^{108}$. ¿Qué memoria contiene entonces su probanza de méritos y servicios? La escritura de recuentos genealógicos se revela connotada por la experiencia política del litigante, su facción y sus asesores legales, y son intrínsecas a las luchas por la legitimidad entre grupos detentadores y grupos aspirantes al poder y a la hegemonía ideológica. Tras las supuestas genealogías cacicales, los indígenas siguieron inmiscuidos en sus propios diálogos locales. En la construcción discursiva de sus linajes, Ayaviri, Guarache, Arriutu o Aymoro fueron activos participantes del proceso político que alcanzaba a distintos sectores coloniales, entre ellos al ámbito hispano.

Por ello, sus probanzas de méritos delinearon el arquetipo del cacique gobernador de la administración colonial, siguiendo las recomendaciones que el Virrey Toledo dirigió en 1575 a los kurakas de Arequipa, Cusco y el Collao, en las cuales fomentaba que «(...) el mejor título para los cacicazgos y sucesión de ellos será el ser mejor cristiano y de más capacidad» ${ }^{109}$. Los hitos discursivos también se impusieron en el recuerdo sobre la temprana conquista. En todos los casos, integrantes de sus supuestos linajes sirvieron a la Corona con gran fidelidad, siendo aparentemente los primeros en haber dado su obediencia:

...[En Cuzco] le dio la obidiencia al dicho marqués, juntamente con el dicho inga Mango Capac. Don Juan Colque Guarache [1575] ${ }^{110}$.

\footnotetext{
108 Jurado, 2011.

109 Sarabia Viejo, 1986, vol. II: 91-95.

110 "Primera Información hecha por don Juan Colque Guarache [1575]", Espinoza Soriano, 1981: 237.
} 
...el primero que dio la obediencia y que persuadió fue de parecer que diesen la obediencia. Don Fernando Ayavire y Velasco [1583] ${ }^{111}$.

...[Moroco, antepasado del litigante] fue el primero que dio la obediencia al Rey nuestro señor. Don Fernando Ayra de Arriutu [1638] ${ }^{112}$.

o bien, revelando la ubicación de las minas auríferas de Porco ${ }^{113}$ :

...fue en descubrir las minas de Porco que antes eran del inga y para su labor dio muchos indios. Don Juan Colque Guarache [1575] ${ }^{114}$.

...el dicho Cuysara descubrió y dio noticia a los dichos capitanes de las minas de Porco que heran del ynga. Don Fernando Ayavire y Velasco [1583] ${ }^{115}$.

O brindando abastecimiento a las tropas realistas durante las Guerras Civiles (1541-1548), minimizando el apoyo brindado a Gonzalo Pizarro en su rebelión:

...cuando se reveló Gonzalo Pizarro, al servicio de Su Majestad puso chasques. Don Juan Colque Guarache [1575] ${ }^{116}$.

...en los rebeliones y motines que hubo entre los conquistadores siempre acudió a la banda de Su Majestad con muchos indios [...] y dio mucha suma de comida que se llevó en carneros al campo de Su Majestad. Don Fernando Ayra de Arriutu $[1638]^{117}$.

...sirvio a Su Magestad como su leal vasallo como consta de una Real Cedula del Señor Emperador don Carlos Quinto dada en Valladolid [...] a 20 de octubre de 1555 en que le elije por Alcalde Maior de los Quatro Suios. Don José Fernández Guarache $[1719]^{118}$.

111 "Probanza de méritos y servicios de don Fernando Ayavire y Velasco, cacique gobernador del repartimiento de Sacaca", Memorial de Charcas, 1986: 67.

112 "Probanza de don Fernando Ayra de Ariutu, cacique y gobernador de Pocoata" [1638], Platt, Bouysse-Cassagne y Harris, 2006: 731.

113 La autoría del descubrimiento de las minas de Porco a los españoles constituyó un terreno confuso y disputado por distintos actores sociales frente a la justicia colonial. Si bien la probanza de méritos y servicios de don Fernando Ayavire y Velasco [1583] aseveraba que fue el líder charka Coysara quien había proporcionado la información -al igual que el Memorial de Charcas [1582]-, documentación del año 1573 guardaba ese lugar para el sumo sacerdote de los incas, Villac Umu. Guillén, 1974: 15.

114 "Primera Información hecha por don Juan Colque Guarache [1575]", Espinoza Soriano, 1981: 238.

115 "Probanza de méritos y servicios de don Fernando Ayavire y Velasco, cacique gobernador del repartimiento de Sacaca", Memorial de Charcas, 1986: 68.

116 "Primera Información hecha por don Juan Colque Guarache [1575]", Espinoza Soriano, 1981: 238.

117 "Probanza de don Fernando Ayra de Ariutu, cacique y gobernador de Pocoata" [1638], Platt, Bouysse-Cassagne y Harris, 2006: 731.

118 ALP, PP, Juzgado 1730-1749, caja 11, f. 3v. 
Tras las genealogías particulares se delinea el arquetipo del kuraka colonial hispanizado, descendiente de estirpes señoriales patrilocales, fieles servidores del Rey y devotos cristianos. Subyace en ellas un mensaje de sujeción, de continuidad, de leal servicio a Su Majestad tanto como al Inca, de distinciones y mercedes, de prestigio y de jerarquía. Sin embargo, tras los conceptos castellanos de hidalguía, linaje, casa, honor, mayorazgo, méritos y herencia, las probanzas de méritos cacicales contienen asimismo un mensaje de legitimidad, una promesa de hegemonía sobre poblaciones extensas, un deseo de autonomía y de consagración hereditaria.

\section{CONSIDERACIONES FINALES}

La historiografía andina ha llamado ampliamente la atención sobre la rapidez con la cual los líderes indígenas participaron en la justicia colonial, pleiteando por intereses individuales, de linaje o de parcialidades más amplias. En todo caso, el uso del sistema legal colonial impuso la traducción de su propia historia a la palabra escrita y en idioma castellano, usando un formato legal con fórmulas establecidas, etapas de presentación, costos onerosos y la interacción con distintos intermediarios, como notarios, intérpretes, testigos y representantes legales.

Para muchos de ellos, la batalla jurídica era central para obtener, conservar y/o transmitir roles de liderazgo, mercedes y beneficios materiales y simbólicos específicos. Asesorados por escribanos, procuradores y consejeros especializados en el ámbito legal, numerosos kurakas de la jurisdicción de la Audiencia de Charcas hicieron propio el modelo de probanzas de méritos y servicios de la nobleza hispana, dando forma a un discurso jerárquico que los posicionaba frente a la justicia colonial. En ellas, el recuerdo del pasado prehispánico se estructuró bajo la forma de linajes de señores andinos que, cual casas nobiliarias castellanas, concentraban solar conocido, cargos en la administración hegemónica, descendencias legítimas por vía de varón, estratégicos parentescos e importantes símbolos de prestigio. En este proceso de construcción de un relato genealógico, los notarios y diversos asesores legales tuvieron un rol central al momento de aconsejar la transmisión de la memoria de acuerdo a las cambiantes reglamentaciones coloniales, los formulismos legales y las necesidades e intereses concretos de los pleitistas. Se ha resaltado en este trabajo que el contenido de las probanzas de méritos y servicios, en tanto documento legal específico, debía guiarse por fórmulas y argumentaciones que orientaban, estructuraban y volvían válido su relato en términos legales. 
De la lectura comparativa de las probanzas de méritos y servicios de renombrados líderes étnicos de Charcas colonial en el amplio período que se extiende entre los años 1574 y 1719, se delinea una élite ladina poderosa, ocupante de cargos importantes en el gobierno de la república de indios, con derroteros históricos similares. Merced a la mediación de diferentes actores sociales especializados en aspectos legales, se impuso la imagen de un líder indígena colonial virtuoso, cristiano, valiente, heredero de un linaje prehispánico central en el gobierno del Tawantinsuyu, aliado pacífico y recompensado por el Inca, ostentador de bienes de prestigio y fama pública y notoria; todas ellas cualidades que los tratados de hidalguía y los manuales para escribanos recomendaban destacar e incorporar en las probanzas de méritos nobiliarias. Así, un modelo de buen kuraka colonial sumado al arquetipo del líder andino juega dentro del andamiaje brindado por el formulismo notarial. Mediante la ayuda y consejo de sus notarios, líderes indígenas diversos recrearon la memoria social y genealógica, siguiendo las formas discursivas propias de las probanzas de méritos y servicios como documento legal. Esta interpretación no invalida la lectura del contenido mismo del documento, sino que enriquece la mirada interpretativa al rescatar el complejo contexto colonial en el cual actúan los peticionarios. Las formas legales estaban prescritas; sin embargo, el modo en el que se elaboraba dicho discurso permitía a los kurakas y a sus facciones espacios a construir.

\section{BIBLIOGRAFÍA}

Abercrombie, Thomas, "Tributes to Bad Conscience: Charity, Restitution, and Inheritance in Cacique and Encomendero Testaments of Sixteenth-Century Charcas", Susan Kellogg, y Mathew Restall (eds.), Dead Giveaway: Indigenous Testaments of Colonial Mesoamerica and the Andes, Salt Lake City, University of Utah Press, 1998: 249-281.

Abercrombie, Thomas, Caminos de la memoria y del poder. Etnografia e historia de una comunidad andina, La Paz, Sierpe, 2006.

Álvarez-Coca González, María, "La fe pública en España. Registros y notarías. Sus fondos. Organización y descripción”, Boletín de la Anabad, XXXVII/1-2 (Madrid, 1987): 7-67.

Álvarez-Ossorio Alvariño, Antonio, "El arte de medrar en la corte: rey, nobleza y el código de honor", Francisco Chacón Jiménez y Juan Hernández Franco (eds.), Familias, poderosos y oligarquías, Murcia, Universidad de Murcia, 2001: 39-60. 
Álvarez-Ossorio Alvariño, Antonio, "Las esferas de la corte: príncipe, nobleza y mudanza en la jerarquía”, Francisco Chacón Jiménez y Nuno Monteiro (eds.), Poder y movilidad social: cortesanos, religiosos y oligarquías en la Península Ibérica (siglos XV-XIX), Madrid, CSIC/Universidad de Murcia, 2006: 129-214.

Atienza Hernández, Ignacio, "La memoria construida: nobleza y genealogía de la casa y la villa de Osuna", Apuntes 2: Apuntes y documentos para una historia de Osuna, 2 (Osuna, 1998): 7-26.

Briones, Claudia, "Con la tradición de todas las generaciones pasadas gravitando sobre la mente de los vivos: usos del pasado e invención de la tradición", RUNA, XXI (Buenos Aires, 1994): 99-129.

Burns, Kathryn, "Notaries, Truth, and Consequences", American Historical Review, 110/2 (Indiana, 2005): 350-379.

Burns, Kathryn, Into the Archive. Writing and Power in Colonial Perú, Durham and London, Duke University Press, 2010.

Capoche, Luis, Relación general de la Villa imperial de Potosí [1585], Madrid, Biblioteca de Autores Españoles, 1959.

Chacón Jiménez, Francisco y Hernández Franco, Juan, “Introducción”, Francisco Chacón Jiménez y Juan Hernández Franco (eds.), Poder, familia y consanguinidad en la España del Antiguo Régimen, Barcelona, Anthropos, 1992: 7-14.

Choque Canqui, Roberto, "Cacicazgo aymara de Pakaxa”, Estudios Bolivianos, 4 (La Paz, 1997): 5-75.

Choque Canqui, Roberto, Jesús de Machaqa: la marka rebelde, La Paz, Plural, 2003.

Covarrubias Orozco, Sebastián de, Tesoro de la lengua Castellana, o Española [1611], Barcelona, S. A. Horta, 1943.

Del Río, Mercedes, "Simbolismo y poder en Tapacarí”, Revista Andina, 8/1 (Cusco, 1990): 77-113.

Díaz Rementería, Carlos, El cacique en el Virreinato del Perú. Estudio histórico-jurídico, Sevilla, Universidad de Sevilla, 1977.

Diez de San Miguel, Garci, Visita hecha a la provincia de Chucuito [1567], Lima, Casa de la Cultura, 1964.

Espinoza Soriano, Waldemar, "El 'Memorial' de Charcas: crónica inédita de 1582”, Cantuta. Revista Nacional de Educación (Chosica, 1969): 117-152.

Espinoza Soriano, Waldemar, "El reino aymara de Quillaca-Asanaque, siglos XV y XVI”, Revista del Museo Nacional de Lima, XLV (Lima, 1981): 175-274.

González de Torneo, Francisco, Practiga de escrivanos que contiene la iudicial, y orden de examinar testigos en causas civiles, y hidalguías, y causas criminales, y escrituras publicas en estilo estenso, y quentas, y particiones de bienes, y execuciones de cartas executorias [1587], http://books.google.com.ar/books?id=Bl- 
$J H d V S Z K n o C \& p g=R A 8-P T 311 \& d q=$ francisco + gonzalez+de+torneo $\& h l=$ $e s-419 \& s a=X \& e i=f 0 y X U 6 f C D K q q s A S u 1 Y G A A Q \& v e d=0 C B 4 Q 6 A E w A Q \# v=$ onepage $\& q=$ francisco $\% 20$ gonzalez $\% 20$ de\%20torneo $\& f=$ false Fecha de consulta: junio de 2014.

Graña, Mario, “'Bastardo, mañoso, sagaz y ladino'. Caciques, pleitos y agravios en el surandino. Don Fernando Ayavire y Velasco contra don Juan Colque Guarache. Charcas, siglo XVI", Anuario del Archivo y Biblioteca Nacionales de Bolivia (Sucre, 2000): 541-556.

Graña, Mario, "La verdad asediada. Discursos de y para el poder. Escritura, institucionalización y élites indígenas surandinas, Charkas, siglo XVI", Andes, antropología e historia, 12 (Salta, 2001): 123-137.

Guajardo-Fajardo Carmona, María de los Ángeles, Escribanos en Indias durante la primera mitad del siglo XVI, España, Concejo General del Notariado, 1995.

Guamán Poma de Ayala, Felipe, Nueva crónica y buen gobierno [1615], Madrid, Historia 16, 1987.

Guillén, Edmundo, Versión Inca de la conquista, Lima, Editorial Milla Batres S. A, 1974.

Halbwachs, Maurice, La memoire collective, Paris, PUF, 1968.

Julien, Catherine, Reading Inca History, Iowa, University of Iowa Press, 2000.

Jurado, María Carolina, "Don Pedro de Dueñas, indio lengua. Un estudio de caso de la interpretación lingüística andino-colonial en el siglo XVII", Anuario del Archivo y Biblioteca Nacional de Bolivia, 16 (Sucre, 2010): 285-309.

Jurado, María Carolina, “Autoridades étnicas menores y territorios. El impacto de la fragmentación colonial en las bases del poder. Macha (norte de Potosí), siglos XVI-XVII", Tesis Doctoral Inédita, Facultad de Filosofía y Letras, Universidad de Buenos Aires, 2011.

Jurado, María Carolina: “"(...) todos descendientes de una misma cassa y sepa'. Discursos cacicales e información censal en torno a las casas del repartimiento de Macha (Norte de Potosí), siglo XVII", Presta, Ana María (ed.), Aportes multidisciplinarios al estudio de los colectivos étnicos Surandinos. Reflexiones sobre Qaraqara-Charka tres años después, La Paz/Lima, Plural Editores/IFEA, 2013: 373-395.

Klapisch-Zuber, Christiane, "L'invention du passé familial à Florence (XIVe-XVe s.)", Actes des Congrès de la Société des historiens médiévistes de l'enseignement supérieur public, 13e Congrès, Aix-en-Provence, 1982: 95-118, /web/revues/ home/prescript/article/shmes_1261-9078_1983_act_13_1_1388 Fecha de consulta: junio de 2014.

Leonard, Irving, Los libros del conquistador, México, FCE, 1996. 
Levillier, Roberto, Gobernantes del Perú. Cartas y papeles, Madrid, Imprenta de Juan Pueyo, 1924.

Lockhart, James, El mundo hispanoperuano, 1532-1560, México, FCE, 1982.

Lovett, Albert, Philip II and Mateo Vázquez de Leca: The Government of Spain (1572-1591), Ginebra, Droz, 1977.

Luján Muñoz, Jorge, "La literatura notarial en España e Hispanoamérica, 1500-1820”, Anuario de Estudios Americanos, 38 (Sevilla, 1981): 101-116.

Macleod, Murdo, "Self-Promotion: The Relaciones de Meritos y Servicios and Their Historical and Political Interpretation", Colonial Latin American Historical Review, 7 (Albuquerque, 1998): 25-42.

Martínez Cereceda, José Luis, "Textos y palabras. Cuatro documentos del siglo XVI", Ana M. Prest (ed. y comp.), Espacio, Etnías, Frontera. Atenuaciones politicas en el sur del Tawantinsuyu, siglos XV-XVIII, Sucre, Ediciones ASUR, 1995: 251-284.

Martínez Cereceda, José Luis, Autoridades en los Andes, los atributos del Señor, Lima, Pontificia Universidad Católica del Perú, 1995.

Matienzo, Juan de, Gobierno del Perú [1567], Paris-Lima, IFEA, 1967.

Medelius, Mónica y de la Puente Luna, José, “Curacas, bienes y quipus en un documento toledano (Jauja, 1570)", Histórica, XXVIII/2 (Lima, 2004): 35-82.

Medinaccelli, Ximena y Arze, Silvia, "Los mallkus de Charkas. Redes de poder en el norte de Potosí (siglos XVI y XVII)", Estudios Bolivianos, 2 (La Paz, 1996): 283-319.

Medinacelli, Ximena y Arze, Silvia, "Prestigio y poder en élites indígenas en situación colonial: el norte de Potosí-Bolivia en el siglo XVII", Latin American Literary Review, 52 (Pittsburgh, 1998): 153-173.

Medinacelli, Ximena, "La ambigüedad del discurso político de las autoridades étnicas en el siglo XVI. Una propuesta de lectura de la probanza de los Colque Guarache de Quillacas", Revista Andina, 38 (Cusco, 2004): 87-104.

Memorial de Charcas, Trascripción paleográfica de Margarita Suárez, manuscrito, 1986.

Mignolo, Walter, "La semiosis colonial: la dialéctica entre representaciones fracturadas y hermenéuticas pluritópicas", Beatriz González Stephan y Lucía Costigan (eds.), Crítica y descolonización: el sujeto en la cultura latinoamericana, Caracas, Universidad Simón Bolívar-The Ohio State University, 1992a: 27-47.

Mignolo, Walter, "The Darker Side of the Renaissance: Colonization and the Discontinuity of the Classical Tradition", Renaissance Quarterly, $45 / 4$ (Nueva York, 1992b): 808-828.

Monterroso y Alvarado, Gabriel, Pratica civil y criminal y instrucion de escrivanos dividida en nueve tratados [1563], http://books.google.com.ar/books?id=jsfL- 
VA0RCy 4 C \&pg $=$ PP $9 \& d q=$ Monterroso $+y+A l v a r a d o \& h l=e s-419 \& s a=$

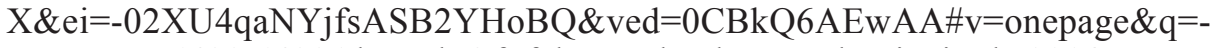
Monterroso\%20y\%20Alvarado\&f=false Fecha de consulta: junio de 2014.

Morrone, Ariel, "Legitimidad, genealogía y memoria en los Andes meridionales: los Fernández Guarachi de Jesús de Machaca (Pacajes, siglos XVI-XVII)", Memoria Americana, 18/2 (Buenos Aires, 2010): 211-237.

Murra, John, "La función del tejido en varios contextos sociales y políticos", John Murra Formaciones económicas y políticas del mundo andino, Lima, IEP, 1975: 145-170.

Murra, John, "La correspondencia entre un 'capitán de la mita' y su apoderado en Potosí”, Historia y Cultura, 3 (La Paz, 1978): 45-58.

Murra, John, "Litigation over the Rights of 'Natural Lords' in Early Colonial Courts in the Andes", Elizabeth Hill-Boone y Tom Cummins (eds.), Native Traditions in the Postconquest World. A Symposium at Dumbarton Oaks, Washington, Dumbarton Oaks, 1998: 55-62.

Nora, Pierre, "Entre Mémoire et Histoire. La problématique des lieux", Pierre Nora (dir.), Les lieux de mémoire, vol. I, París, Gallimard, 1984: 15-42.

Ondegardo, Polo, "Traslado de un cartapacio a manera de borrador que quedó en los papeles del Lic. Polo de Ondegardo cerca del linaje de los Ingas y como conquistaron”, Colección de libros y documentos referentes a la historia del Perú, vol. IV, Lima, Imprenta y Librería Sanmarti y cia, 1917: 116-117.

Pärssinen, Martti, Tawantinsuyu. El estado inca y su organización política, Lima, IFEA-PUCP, 2003.

Pease, Franklin, Del Tawantinsuyu a la Historia del Perú, Lima, IEP, 1989.

Pérez, Joseph, "La aristocracia castellana en el siglo XVI", María del Carmen Iglesias (coord.), Nobleza y sociedad en la España Moderna, Oviedo, Ediciones Nobel, 1996: 53-71.

Platt, Tristan, "Entre Ch'axwa y Muxsa. Para una historia del pensamiento político aymara", Thérèse Bouysse-Cassagne, Olivia Harris, Tristan Platt y Verónica Cereceda (eds.), Tres reflexiones sobre el pensamiento andino, La Paz, HISBOL, 1987: 61-131.

Platt, Tristan, Bouysse-Cassagne, Thérèse y Harris, Olivia, Qaraqara-Charka. Mallku, Inka y Rey en la provincia de Charcas (siglos XV-XVII). Historia antropológica de una confederación aymara, La Paz, IFEA/Plural, 2006.

Presta, Ana María, Encomienda, familia y negocios en Charcas colonial (Bolivia). Los encomenderos de La Plata, 1550-1600, Lima, IEP/BCRP, 2000.

Presta, Ana M., “'Por el mucho que tengo'. Matrimonio indígena, poliginia y vida conyugal en Charcas, siglos XVI-XVII", Mónica Ghirardi (coord.), Familias ibe- 
roamericanas, ayer y hoy. Una mirada interdisciplinaria, Córdoba, ALAP, 2008: 45-61.

Ramírez, Susan, "Historia y memoria: la construcción de las tradiciones dinásticas andinas", Revista de Indias, LXVI/236 (Madrid, 2006): 13-56.

Rappaport, Joanne, Cumbe Reborn. An Andean Ethnography of History, Chicago, The University of Chicago Press, 1994.

Recopilación de leyes de los reinos de las indias mandadas imprimir y publicar por la Magestad Católica del Rey Don Carlos III nuestro Señor. http://www.congreso. gob.pe/ntley/LeyIndiaP.htm Fecha de consulta: junio de 2014.

Rodríguez Sánchez, Ángel, "El poder y la familia. Formas de control y de consanguinidad en la Extremadura de los tiempos modernos", Francisco Chacón Jiménez y Juan Hernández Franco (eds.), Poder, familia y consanguinidad en la España del Antiguo Régimen, Barcelona, Anthropos, 1992: 15-34.

Rowe, John, "Probanza de los incas nietos de conquistadores", Histórica, IX/2 (Lima, 1985): 193-245.

Ruiz García, Elisa, "La carta ejecutoria de hidalguía: un espacio gráfico privilegiado”, Miguel Laredo Quesada (coord.), Estudios de genealogía, heráldica y nobiliaria, Madrid, Universidad Complutense, 2006: 251-276.

Saignes, Thierry, "De la borrachera al retrato: los caciques andinos entre dos legitimidades (Charcas)", Revista Andina, 5 (Cusco, 1987): 139-170.

Santillán, Hernando, "Relación del origen, descendencia, política y gobierno de los Incas [1563]", Francisco Esteve Barba (ed.), Crónicas peruanas de interés indígena, Madrid, Ediciones Atlas, 1968: 7-277.

Sarabia Viejo, María Justina, Francisco de Toledo. Disposiciones gubernativas para el Virreinato del Perú, 1569-1574, Sevilla, EEHA, 1986.

Sarmiento de Gamboa, Pedro, Historia general de los Incas [1572], Buenos Aires, Emecé Editores, 1942.

Solórzano y Pereyra, Juan de, Política Indiana [1648], Madrid, Biblioteca de Autores Españoles, 1972.

Stern, Steve, Los pueblos indígenas del Perú y el desafío de la conquista española. Huamanga hasta 1640, Madrid, Alianza Editorial, 1982.

Fecha de recepción: 10 de agosto de 2012.

Fecha de aceptación: 20 de diciembre de 2012. 


\section{"Descendants of the First". Probanzas of Merits and Services and the Genealogy of Indigenous Leaders. Audiencia of Charcas, 1574-1719}

The aim of this article is to study the «Probanzas» of merits and services of well-known chiefdom lineages of colonial Charcas from a questioning view which takes into consideration how the writing of the document was developed, looking at the actions of notaries, solicitors and legal advisers as key players in the adaptation and transmission of its discourse. The comparative reading of different "probanzas» of merits reveals the imitation of a leadership model in the interstices of colonial Spanish formulae. Therefore, the paper proposes some reflections on the uses of the "probanzas» of merits and services for the knowledge of Pre-Hispanic and colonial past.

KEY WORDS: proof of merits and services; notaries; genealogy; indigenous leaders; colonial Charcas. 